\title{
Differential effects of information technology on competitive positioning
}

\author{
Bayer, Michael; Haug, Anders; Hvam, Lars
}

Published in:

Industrial Management \& Data Systems

Link to article, DOI:

10.1108/IMDS-01-2020-0037

Publication date:

2020

Document Version

Publisher's PDF, also known as Version of record

Link back to DTU Orbit

Citation (APA):

Bayer, M., Haug, A., \& Hvam, L. (2020). Differential effects of information technology on competitive positioning. Industrial Management \& Data Systems, 120(10), 1923-1939. https://doi.org/10.1108/IMDS-01-2020-0037

\section{General rights}

Copyright and moral rights for the publications made accessible in the public portal are retained by the authors and/or other copyright owners and it is a condition of accessing publications that users recognise and abide by the legal requirements associated with these rights.

- Users may download and print one copy of any publication from the public portal for the purpose of private study or research.

- You may not further distribute the material or use it for any profit-making activity or commercial gain

- You may freely distribute the URL identifying the publication in the public portal

If you believe that this document breaches copyright please contact us providing details, and we will remove access to the work immediately and investigate your claim. 


\section{Differential effects of information technology on competitive positioning}

Effects of IT on competitive positioning

1923

Michael Bayer

Management Science, Technical University of Denmark, Lyngby, Denmark

Anders Haug

Department of Entrepreneurship and Relationship Management, University of Southern Denmark, Odense, Denmark, and

Lars Hvam

Management Science, Technical University of Denmark, Lyngby, Denmark

\begin{abstract}
Purpose - Information technology (IT), combined with complementary resources, can contribute to companies' competitive positioning. However, to assess the contribution of IT to value with respect to the contribution of complementary resources, it is crucial to understand the means by which IT creates value.

Design/methodology/approach - This paper synthesizes empirical research on the inherent capabilities of IT and their moderating role to build an integrative model.

Findings - We found that IT creates value through three inherent capabilities: transactional, exchange and codification capabilities. These capabilities can be regarded as moderators of the relationship between IT and competitive advantage. This moderating role of IT in competitive positioning is illustrated by examples from previous empirical publications.

Research limitations/implications - The paper contributes to IT business value (ITBV) literature by developing an integrative model that (1) conceptualizes an aspect of IT value creation, which, thus far, has received only limited attention (namely, inherent capabilities) and (2) illustrates the moderating role of these capabilities in competitive positioning.

Practical implications - Inherent capabilities provide the theoretical foundation for a nuanced understanding of IT contribution with respect to complementary resources. This understanding may support IT executives in deriving adequate measurements and, thus, account for the differential effects of IT. Originality/value - Compared to the literature, the proposed model represents a more coherent and holistic perspective of ITBV. Thus, the model may constitute a foundation for future ITBV research and promote more detailed analytic perspectives of ITBV.
\end{abstract}

Keywords Business value, Competitive advantage, Information technology, Inherent capabilities, Value creation

Paper type Research paper

\section{Introduction}

Contrary to early studies (Hackett, 1990), recent studies have reported a positive and significant relationship between information technology (IT) investments and productivity (Byrd et al., 2006; Chou et al., 2014; Dedrick et al., 2003) and other operational performance measurements (Hong and Ghobakhloo, 2013; Meixell, 2006). As statistical evidence of the value of IT has become more common, the focus has shifted from whether IT creates value to how and why IT creates value (Neumeier et al., 2017). Researchers commonly agree that IT does not create value, per se. It only creates value in combination with complementary resources, such as humans and processes (Liang et al., 2010; Neumeier et al., 2017). This, in turn, means that IT must be effectively implemented in organizational structures. Therefore, much of the recent IT value research has emphasized contextual factors that influence the effectiveness of IT. Such complementary factors include job training (Barczak et al., 2007), business process engineering (Altinkemer et al., 2011) and management (Khayer et al., 2020;

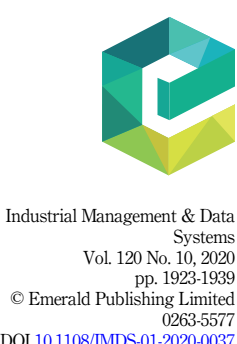

DOI 10.1108/IMDS-01-2020-0037 
IMDS

120,10

1924

Lai et al., 2006). Researching contextual factors not only contributes to a better understanding of how to improve return on IT investment but also helps to explain the varying IT effects across individual firms (Wiengarten et al., 2013).

This research path, however, examines only one aspect of IT value. The other aspect how and why IT creates value - is the actual value contribution of IT in proportion to the contribution of complementary resources. In other words, value can be regarded as the outcome of a multivariable equation in which IT accounts for only one variable despite other complementary resources. The IT variable and its effectiveness can vary as the IT variable is dependent on contextual factors. However, the means by which IT creates value are implicit and fragmented in the current body of literature. Therefore, this paper examines the means by which IT creates value. To avoid confusion with the capabilities of IT departments, which are typically referred to as IT or IS capabilities (Hong and Ghobakhloo, 2013; Ravichandran, 2018), this paper uses the term inherent capabilities of IT. This term was selected because the means by which IT creates value are inherent in IT and only create value in combination with other resources (Liang et al., 2010). Therefore, the inherent capabilities of IT are the actual value creators of IT.

The research perspective described above is widely neglected in the literature, but it is important to advancing our understanding of IT value creation and, thus, developing a more nuanced account of the differential effects of IT (Kim et al., 2018; Schryen, 2013). The need for further research within this field was best described by Mistry (2006), who suggests that "any analysis of the impact of IT in the IT literature may be incomplete if it does not disaggregate the IT variable and examine the impact of IT differentially [on firm performance]" (p. 341). In addition, "each IT [...] type requires a different duration to achieve its value on firm performance because each type has unique characteristics" (Kim et al., 2018, p. 465). This means that different types of IT affect firm performance differently in duration and firm performance measurements. Therefore, this conceptualization aims to provide the theoretical foundation to holistically disaggregate the total IT investments of firms into IT types to account for the differential effects of IT.

To investigate the inherent capabilities of IT and their impact on business value, this research applied Porter's generally accepted building blocks of competitive advantage (Dewett and Jones, 2001; Porter, 1985), i.e. efficiency, quality, innovation and customer responsiveness. Thus, this research goes beyond the typical economic measurements, such as productivity, profitability and revenue, by linking IT to the four differentiating paths on which a company can focus. Specifically, value is defined as an improvement of one of the four dimensions of competitive advantage. Furthermore, the study builds on the widely acknowledged view that IT moderates the relationship between organizational characteristics and organizational outcomes (Dewett and Jones, 2001; Liang et al., 2010). In other words, the intention of this research is to define and describe the moderating role of IT by determining the inherent capabilities of IT (i.e. how IT creates value) and their impact on the four dimensions of competitive advantage (i.e. the value contribution of IT).

The paper contributes to IT business value (ITBV) research by providing a detailed account of the inherent capabilities of IT and describing the moderating role of IT in competitive positioning. Specifically, we organize the ways in which IT can produce business value, which provides future research with a more coherent and holistic perspective of the business value of IT. Although previous researchers have touched on the effect of IT on some of the four dimensions of competitive advantage (Lai et al., 2006), a model that concisely illustrates a holistic view of competitive advantage, moderated by IT, is absent from the literature (Dewett and Jones, 2001; Schryen, 2013). Thus, we aim to develop a model that can be used as a basis for future research to ensure a more comprehensive approach to investigating ITBV. 
2. Methodology

The purpose of the literature search was to identify empirical studies that could be used as the basis for classifying the inherent capabilities of IT with respect to their value contributions to competitive advantage. These aspects have not yet been explicitly collected and organized within the literature, a gap we seek to fill. The review followed Leidner and Kayworth's (2006) methodological approach of developing (1) a strategy for searching the literature, (2) criteria for selecting literature for this review and (3) a scheme for documenting and analyzing the selected literature.

Regarding the search strategy, we decided not to limit the search to articles that explicitly mentioned the term ITBV, as many studies deal with the topic without using this term. However, as ITBV refers only to certain types of value, a general search for value in the context of IT was considered too broad. To identify relevant terms for the literature search, literature on ITBV was inspected, and possible search strategies were discussed with other researchers in the field. The development process of the search string was iterative, alternating between brainstorming keywords and adding additional keywords generated from the literature. This process gave rise to a search delimitation with the purpose of excluding literature that did not address in detail the type of business value in focus. Specifically, the dimensions of Porter's (1985) framework of competitive advantage (i.e. efficiency, quality, innovation and customer responsiveness) were used to delimit the search. The following search string was applied in two relevant databases for management, engineering and information system literature (namely, SCOPUS and Web of Science):

("value creation" OR "IT value" OR "business value" OR "enterprise IT value" OR "IT impact" OR "IT contribution") AND ("information technology" OR "information system") AND (efficiency OR innovation OR quality OR "customer responsiveness").

After duplicates were removed, the search results included 481 journal articles written in English, retrieved on April 24, 2019. The remaining papers were grouped by journal, which, in turn, were sorted from high- to low-ranking journals, according to the Scimago Institutions Rankings 2017 [1]. To limit the number of articles, we focused on articles from the top 20 journals, as well the remaining five journals of the IS basket of eight journals (Lowry et al., 2013) that did not fall among the top 20 journals. The underlying assumption for this selection criterion was that significant inherent capabilities of IT could be derived from this literature selection alone. Thus, the limited article selection comprised 136 papers from 25 journals (Table 1).

After an abstract review of the 136 selected journal articles, 64 articles remained, which discussed the creation of IT value and detailed the value contribution. There were two criteria for full-text reading: the paper had to detail the way in which (how) IT creates value and had to specify the contribution of IT to competitive advantage. After the full-text reading, 30 papers from 12 journals remained (indicated by* in Table 1). These provided the empirical backbone for this paper to describe value creation and the contribution of IT. The results of the literature search and selection strategy are illustrated in Figure 1.

The remaining 30 articles were analyzed using a coding procedure to highlight concepts and sentences related to the inherent IT capabilities. To process the concepts identified, they were grouped into themes, which subsequently were aggregated into dimensions (Gioia et al., 2012). The analysis process is further described in the next section.

\section{An integrative model of IT value creation}

Much research effort has focused on the quantification of business value in economic terms; far less effort, however, has been devoted to the moderating role of IT in competitive positioning. To be competitive and viable in the long run, a company must differentiate itself
Effects of IT on competitive positioning

1925 
Academy of Management Review

Accounting Review

California Management Review

European Journal of Information Systems*

European Journal of Operational Research

Information Systems Journal

1926

Information Systems Research*

International Journal of Production Economics*

Journal of Information Technology*

Journal of Management*

Journal of Management Information Systems*

Journal of Operations Management*

Journal of Product Innovation Management*

Journal of Service Research

Journal of Strategic Information Systems*

Journal of the Academy of Marketing Science

Journal of the Association of Information Systems

Journal of the Travel Research

Management Science*

Manufacturing and Service Operations Management

MIS Quarterly: Management Information Systems*

Omega

Organization Science*

Production and Operations Management

Table 1.

Top 25 journals, alphabetically
Review of Financial Studies

25 journals / 12 journals*

Note(s): *Journals and articles that remained after a full-text reading

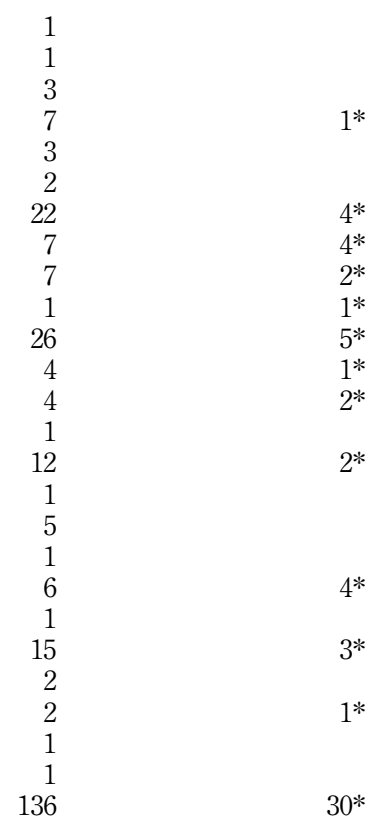

$30 *$
Figure 1.

Steps for selecting articles

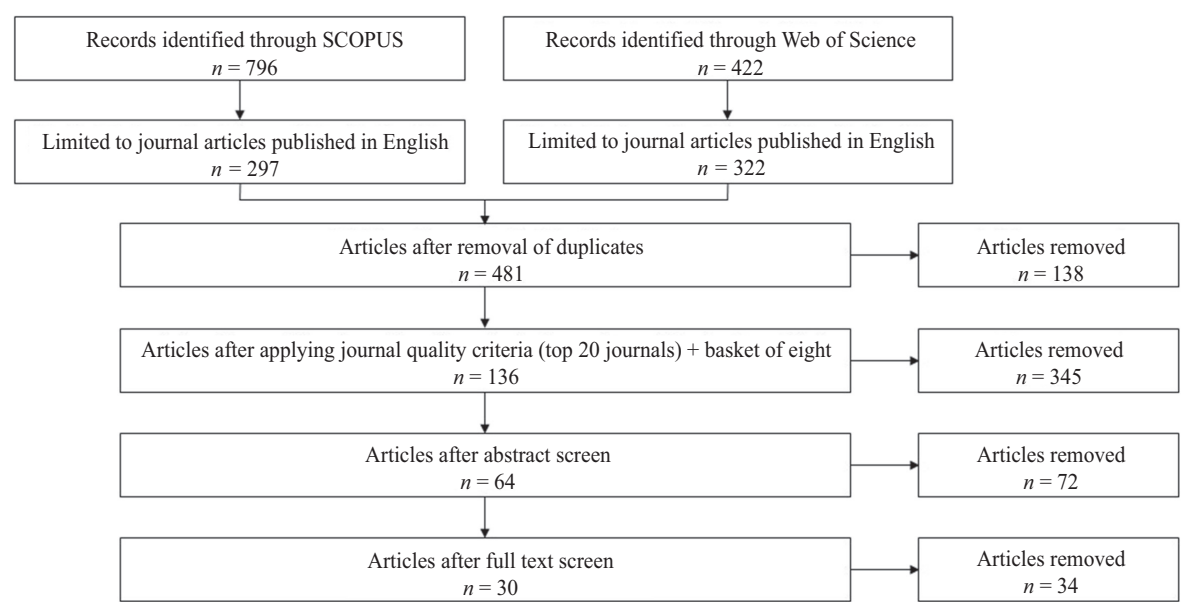

by pursuing either a low-cost or differentiation strategy (Porter, 1985). Both strategies are affected by the four dimensions of competitive advantage: efficiency, quality, innovation and customer responsiveness. As indicated by the number of unique articles identified in the search results $(n=481)$, researchers have extensively addressed the relationship between IT and competitive advantage on some dimensions of competitive advantage individually 
(Dewett and Jones, 2001; Dong and Wu, 2015; Leidner et al., 2010; Mithas et al., 2011). However, the current body of knowledge on the business value of IT, which views IT as a moderator for competitive positioning, is fragmented. Thus, an integrative model that would concisely describe the value creation of IT (i.e. how IT creates value) with respect to the four dimensions of competitive advantage is absent.

Of the 64 articles selected based on the abstract review, only 30 provided adequately detailed descriptions of value creation related to one or more dimensions of competitive advantage. Specifically, although many of the discarded articles examined and even measured the effect of IT on one or more dimensions of competitive advantage, they did not detail how IT created value nor did they specify the nature of the IT under investigation. Therefore, we could not include these papers, as they did not offer empirical evidence sufficient for our inductive work to determine the inherent capabilities of IT.

To increase the transparency of the inductive work, Pang et al.'s (2014) research was taken as an example. The authors describe how governments apply "integrated systems and communication technologies (assets) that enable [the] exchange [of] information [...] with external organizations" (p. 196). Furthermore, they stated that seamless information exchange between municipalities and local municipal agencies, such as fire departments and police, is crucial for guaranteeing effective emergency response services. Therefore, IT in the form of integrated systems and communication technologies "improve[s] the quality of public safety services throughout the county" (Pang et al., 2014, p. 196) through information exchange. This means that one inherent capability of IT is exchanging information, and, as seen in this example, IT can contribute to increased quality.

Table 2 shows the antecedents of the 16 inherent capabilities of IT after abstraction from the application area and industry type, following the previously exemplified procedure. The antecedents, however, were still dependent on the dimensions of efficiency, quality, innovation and customer responsiveness. After we removed redundant categories and performed further abstraction of the competitive advantage dimensions, three predominant categories emerged: transactional, exchange and codification capabilities.

The quantitative part of the analysis is detailed in Table 3. The analysis was constructed as follows: First, each paper that discussed the inherent capabilities of IT and their contribution to competitive advantage received a count. Various combinations of inherent capabilities of IT and the dimensions of competitive advantage could be mentioned within a paper; thus, one paper could obtain multiple counts for various combinations. However, in the event the same combination of inherent capabilities of IT and dimensions of competitive advantage occurred multiple times within a single article, the combination was counted only once. The full table, which is the backbone of this paper, can be found in Appendix 1.

As seen in Table 3, IT as a contributor to efficiency was mentioned most frequently within the articles reviewed (73\%). This was to be expected, given the large amount of extant research on productivity gains from IT investments (Aral et al., 2012). Quality improvements were discussed in $40 \%$ of the papers. As IT typically requires standardized data and processes, increased quality was also expected (Angst et al., 2012). The fostering of innovation by IT was mentioned in only $20 \%$ of the articles and was typically derived from knowledge exchange and increased market insights due to increased information processing (Barczak et al., 2007). Finally, customer responsiveness appeared in $27 \%$ of the articles in association with gathering, storing and processing customer insights to better serve customers' needs (Mithas et al., 2011).

Furthermore, the aggregation of the inherent capabilities of IT across the four dimensions of competitive advantage represented transactional (90\%), exchange $(63 \%)$ and codification $(63 \%)$ capabilities (Table 3). The predominant inherent capability of IT per dimension of competitive advantage was the transactional capability to achieve efficiency gains, 
IMDS
120,10

\section{8}

Quality

Innovation

Customer responsiveness

\section{Exchange capability} Efficiency

Quality

Innovation

Customer responsiveness

Codification capability Efficiency

Quality

Innovation

Table 2.

Antecedents of inherent capabilities of Customer information technology responsiveness
Initial capabilities grouped by the final

three inherent capabilities of IT (themes)

References

Increased ability to process and analyze information for decision-making Increased ability to automate processes for increased output

Increased ability to process information (error processing) to achieve better product or service quality Increased ability to automate alerts (error identification)

Increased ability to process information to identify competitive strength or innovations

Increased ability to process information to visualize the design

Increased ability to process information (strategic processing) to meet customer needs

Increased ability to communicate and collaborate to achieve information synergies

Increased ability to communicate and collaborate to achieve higher product or service quality

Increased ability to communicate and collaborate to achieve information synergies

Increased ability to coordinate and manage remote processes to achieve better outcomes Increased ability to coordinate and manage remote processes to achieve quicker responsiveness

Increased ability to access information quickly

Increased ability to access information in a consistent manner to achieve better decision-making

Increased ability to access organizational memory to achieve innovation

Increased ability to access market requirements to achieve increased responsiveness
Müller et al. (2018), Tambe (2014),

Trantopoulos et al. (2017)

Adjerid et al. (2018), Aral and Weill (2007), Chwelos et al. (2010), Davamanirajan et al. (2006), Fazlollahi and Franke (2018),

Mukhopadhyay et al. (1997), Müller et al. (2018), Zhu and Kraemer (2005)

Gardner et al. (2015), Leidner et al. (2010), Zhu and Kraemer (2005)

Angst et al. (2012), Thorogood et al. (2004)

Saldanha et al. (2017)

Mauerhoefer et al. (2017)

Gardner et al. (2015), Po-An Hsieh et al. (2011), Roberts and Grover (2012)

Chou et al. (2014), Davamanirajan et al. (2006), Dewett and Jones (2001), Fazlollahi and Franke (2018)

Feller et al. (2011), Pang et al. (2014), Reyes et al. (2012)

Dewett and Jones (2001), Dong and Wu (2015), Joshi et al. (2010)

Mauerhoefer et al. (2017)

Barczak et al. (2007), Mithas et al. (2011), Roberts and Grover (2012)

Devaraj and Kohli (2003), DominguezPéry et al. (2013)

Devaraj and Kohli (2000)

Saldanha et al. (2017)

Barczak et al. (2007), Mithas et al. (2011) 
Inherent capability per dimension of competitive advantage

Efficiency

Transactional capability

Exchange capability

Codification capability

Quality

Transactional capability

Exchange capability

Codification capability

Innovation

Transactional capability

Exchange capability

Codification capability

Customer responsiveness

Transactional capability

Exchange capability

Codification capability
Absolute article count

$$
(n=30)
$$

Relative article count $(n=30)$
Effects of IT on competitive positioning

$$
\begin{aligned}
& 70 \% \\
& 40 \% \\
& 37 \% \\
& \\
& 33 \% \\
& 17 \% \\
& 30 \%
\end{aligned}
$$

$13 \%$

$13 \%$

$13 \%$

\begin{tabular}{lll}
\hline Aggregated results & Absolute article count $(n=30)$ & Relative article count $(n=30)$ \\
\hline
\end{tabular}

Dimensions of competitive advantage

Efficiency

Quality

Innovation

Customer responsiveness

$\begin{array}{rr}22 & 73 \% \\ 12 & 40 \% \\ 6 & 20 \% \\ 8 & 27 \% \\ & \\ 27 & \\ 19 & 90 \% \\ 19 & 63 \% \\ & 63 \%\end{array}$

$17 \%$

$20 \%$

$20 \%$

Inherent capabilities of IT

Transactional capability

Exchange capability

Codification capability

Table 3.

Analysis results of the reviewed articles

mentioned in $70 \%$ of the articles (Table 3). The least-mentioned was the combination of all three inherent capabilities of IT regarding increased innovation, which was mentioned only four times in the literature.

The analysis results in Table 3 should be regarded as indicative rather than conclusive, as the selected sample size of empirical publications does not allow for any conclusions about importance to be drawn. This means that a higher count per relationship does not necessarily indicate greater significance. Instead, a high count per relationship simply indicates that this combination was explicitly mentioned more often than other combinations.

Based on the findings shown in Tables 2 and 3, Table 4 provides definitions and examples of the three inherent capabilities of IT. As shown, IT provides business value through these capabilities. For example, business analytics or planning systems provide transactional capabilities, meaning the ability to process, interpret and synthesize information and automate business processes. These systems contribute to efficiency, quality, innovation and customer responsiveness with their transactional capabilities depending on their context and purpose.

The organization of the literature, presented in Tables 3 and 4, led to the development of an integrative model of IT value creation (Figure 2). The model was built on the synthesis of previous research and specifies the inherent capabilities of IT and their contributions to competitive positioning. 


\section{IMDS 120,10}

Definition

Transactional capability

The ability to automate existing business processes and process, interpret and synthesize information

\section{0}

\section{Table 4.}

Definition of inherent capabilities and information technology examples
Exchange capability

The ability to exchange information within and across firms, enabling fragmented entities to connect, communicate and collaborate seamlessly

\section{Codification capability}

The ability to capture and integrate information by making it easy to collect, organize, store and access across the organization
Information technology example

Business analytics, such as data mining (Müller et al., 2018)

Planning systems, such as production and transportation planning (Mauerhoefer et al., 2017)

E-mail (Chou et al., 2014)

Enterprise service bus (Fazlollahi and Franke, 2018)

Video conferencing, such as Skype (Dewett and Jones, 2001)

Data warehousing (Joshi et al., 2010)

Intranet (Dewett and Jones, 2001)
Figure 2.

Information technology value creation cube

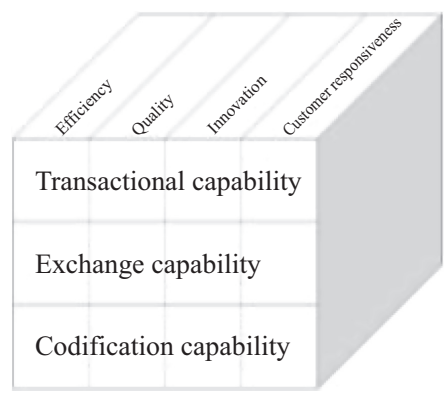

To illustrate the dimensions of the model in Figure 2, a selection of examples identified in the literature is presented in Table 5. The contributions of the conceptualized inherent capabilities of IT to competitive positioning differ depending on the context.

\section{Discussion}

\subsection{Theoretical contributions}

This research contributes to the literature on ITBV by deriving an integrative model (Figure 2) that describes the actual value creation of IT in the four dimensions of competitive advantage. Specifically, this research explicitly defines how IT creates value and adds another aspect of the IT value creation process. These means are referred to in this paper as the inherent capabilities of IT, as they are inherent to IT and contribute to value only when combined with other resources. Thus, the inherent capabilities of IT illustrate how IT contributes to value (Figure 3). Three inherent capabilities of IT were derived from the selected articles (Table 3); these represent an attempt to describe how IT creates value (Neumeier et al., 2017).

The inherent capabilities of IT form the theoretical foundation to disaggregate the sum of IT investments. Previous researchers typically regarded a company's IT investments monolithically, meaning as one IT asset, and linked the sum of IT investments to performance measurements. However, researchers have recently shown that different IT assets affect 
Dimension of competitive advantage

Example from the literature

Transactional capability Efficiency

Quality

Innovation

Customer responsiveness

\section{Exchange capability}

Efficiency

Quality

Innovation

Customer responsiveness

\section{Codification capability}

Efficiency

Quality

Innovation

Customer responsiveness Chwelos et al., 2010)
As labor accounts for the primary cost driver in many industries, IT, with its ability to automate business processes, enables firms to reduce labor costs and, thus, allows companies to operate more efficiently (Aral and Weill, 2007;

Using analytical tools for information processing, such as data mining or error competitive positioning proofing, can lead to the detection and reduction of errors within internal processes. Once errors are detected and accurately resolved, IT contributes to process, product and service quality (Gardner et al., 2015)

Gathering, interpreting and synthesizing objective data for organizational planning enables firms to scan the competitive environment efficiently and effectively to identify innovation opportunities (Joshi et al., 2010)

Sales analysis and data mining of customer reactions to firms' offerings can help firms to improve their products and services to better address customers' needs (Aral and Weill, 2007; Roberts and Grover, 2012)

The sharing of patients' medical information between disparate healthcare providers informs the providers about previous diagnostics and treatment in a timely manner. Informed by patients' medical history, providers can avoid redundant treatments and, thus, increase the efficiency and effectiveness of the treatment process (Adjerid et al., 2018)

Collaboration and seamless information exchange between local municipal agencies, such as the fire department and police, can improve the quality of public safety services (Pang et al., 2014)

IT that supports direct interaction between employees by creating seamless networks of people, devices and knowledge fosters knowledge exchange and, thus, innovation (Joshi et al., 2010)

Specifically, the use of IT tools to facilitate cooperation and disseminate knowledge about customers among team members and suppliers has been shown to have positive effects on product design and, thus, in meeting customer needs (Barczak et al., 2007; Mithas et al., 2011)

Utilizing data access systems allows firms to search and absorb knowledge from external knowledge sources to promote efficiency-enhancing activities and lower production costs (Trantopoulos et al., 2017)

Decision support systems are designed to store day-to-day care data for each admitted patient. Having documented clinical data about treatment enables operational decision-makers to identify best practices and, thus, improve the quality of care (Devaraj and Kohli, 2000)

IT facilitates organizational memory by capturing and integrating explicit knowledge. Such organizational memory can exceed the capacity of individuals; therefore, IT creates a larger and richer pool of codified knowledge. Due to the accessibility of that codified knowledge by individuals and teams, IT promotes innovation (Dewett and Jones, 2001)

Firms need to leverage the voice of their customer to understand and address the diverse needs of customer segments. Therefore, it is crucial to capture information about customers to gain market intelligence for increased customer responsiveness (Mithas et al., 2011)
Table 5.

Contextual examples of inherent capabilities 


\section{IMDS \\ 120,10}

\section{2}

Figure 3.

Inherent capabilities of information technology in context

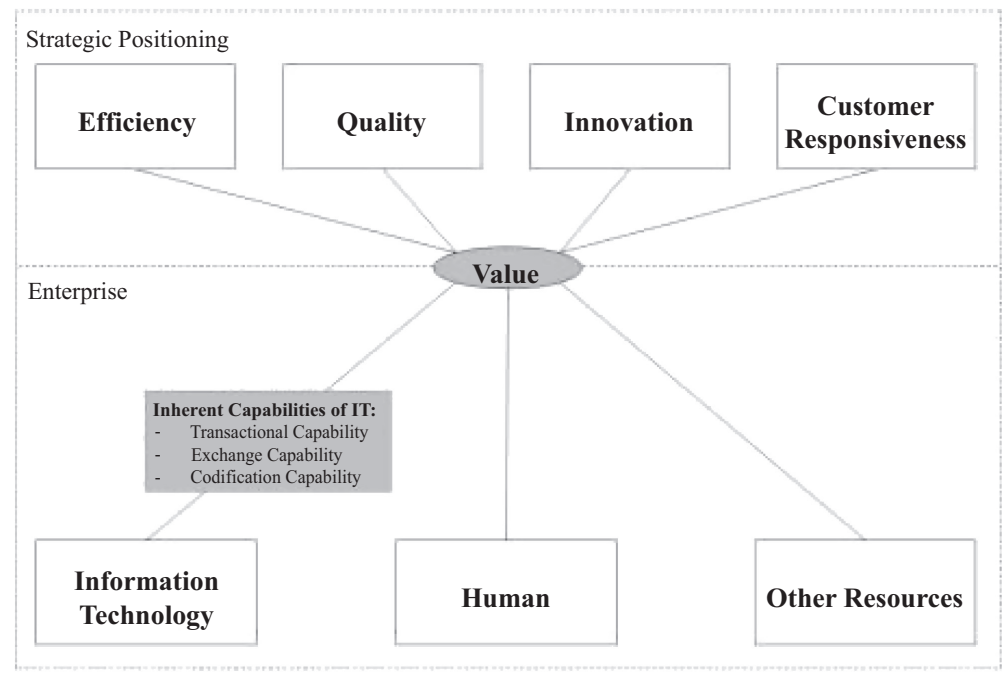

different performance measurements (Kim et al., 2018; Mistry, 2006). Therefore, with the conceptualization of the inherent capabilities of IT, this paper contributes to a nuanced understanding of IT value creation and, thus, may provide a theoretical foundation for future studies to "propose more exhaustive frameworks [.. . ] to further advance the understanding of IT capital's differential effects on firm performance" (Kim et al., 2018, p. 465).

Furthermore, this research extends beyond the financial value of IT by illustrating the diverse facets of the moderating role of IT in competitive positioning (Table 4). Although previous researchers have touched on the effect of IT on some of the four dimensions of competitive advantage (Lai et al., 2006), a model that concisely illustrates a holistic view of competitive advantage, moderated by IT, is absent in the literature (Dewett and Jones, 2001; Schryen, 2013). Therefore, we conceptualized an integrative model that, first, details the inherent capabilities of IT, thus describing how IT creates value, and second, illustrates the moderating role of IT in competitive positioning on the four dimensions of competitive advantage. This work constitutes a novel attempt to shed light on the value creation process of IT and the value contribution of IT to competitive positioning.

In summary, this paper contributes to the ITBV literature by providing a detailed account of the inherent capabilities of IT and describing the moderating role of IT in competitive positioning. Specifically, the developed model provides future researchers with a more coherent and holistic perspective of the business value of IT. This model may be used as a basis for future research to ensure a more nuanced approach to investigating ITBV. Specifically, no existing studies that considered all 16 inherent capabilities of IT were identified in the literature, only subsets. Therefore, use of the proposed model may promote research with a more detailed analytic perspective of ITBV.

\subsection{Contributions to practice}

Practitioners may use this research as an overview of the differential effects of IT, which extend beyond the typically assumed efficiency and productivity gains (Aral and Weill, 2007). Specifically, the integrative model (Figure 2) may draw managers' attention to two central aspects of IT value creation: (1) applied in the right context, IT may contribute to efficiency, quality, innovation and customer responsiveness improvements; and (2) IT may 
have a moderating role in competitive positioning. The emphasized aspect of IT value creation (namely, the inherent capabilities of IT) and its implications for the differential impact of IT may sensitize managers when they measure the value of IT. Put differently, IT investments do not necessarily affect firms' productivity through efficiency enhancements if the IT investment has an effect on service quality or customer responsiveness.

The inherent capabilities of IT may also provide practitioners with additional insights into the effect of IT at the process level, which may lead to a more nuanced understanding of IT value creation and its potential effects. Overall, the nuanced view on value creation combined with the overview of the differential effects of IT may advance knowledge on the effects of IT and possibly enable practitioners to perform a complete assessment of the benefits of IT (Kim et al., 2018; Melville et al., 2004; Mistry, 2006; Schryen, 2013; Xue et al., 2012). The practical relevance of the model of inherent capabilities is illustrated by examples from the literature (Table 5).

To operationalize the integrative model, practitioners may organize IT assets under the two dimensions of the integrative model: (1) the building blocks of competitive advantage and (2) the inherent capabilities of IT. To do so, two types of data should be available: (1) the IT application catalogue, depicting all IT assets (typically owned by IT asset management); and (2) the business process blueprint or business capability model to understand the context of the IT assets. If the latter is not formalized, or additional information is needed to be able to categorize individual IT assets, interviews with process and service owners should be conducted.

Based on the classification of IT assets, the implications for practitioners are twofold. First, the organization of IT assets along the two axes indicates whether the current IT landscape appropriately supports firms' strategies and where future IT investments should be placed. Therefore, the overview of IT assets allows practitioners to analyze current business-IT alignment and to derive roadmaps for future IT investments. Second, for each category of the integrative model, such as transactional capability and efficiency, appropriate key performance indicators can be developed to assess the value of IT. Using the definitions of the inherent capabilities of IT (Table 4) and the empirical examples of each category (Table 5), practitioners may assess the value of IT through an improved understanding of the actual effect of each category within the integrative model.

\subsection{Limitations and future research}

The article has three potential limitations. The first limitation is that the study was restricted to 25 top journals. Although these journals cover a large and significant portion of the work in this research field, wider coverage of journals could provide additional insights. However, it maybe expected that studies published in top journals, because of their rigor, would have identified the inherent capabilities of IT along the dimensions of competitive advantage.

The second limitation concerns the search strategy, which used Porter's four building blocks of competitive advantage (efficiency, quality, innovation and customer responsiveness) to delimit the search. In this context, it is possible that excluding this delimitation would have produced additional results. However, this seems unlikely, as the four building blocks are generally accepted dimensions used to describe organizational outcomes (Dewett and Jones, 2001). Furthermore, in cases where IT was linked to other organizational outcomes - such as customer satisfaction, productivity and revenue described in detail, it can be logically asserted that the dimension of quality or customer responsiveness was mentioned when discussing customer satisfaction or revenue, whereas efficiency may have been detailed in the context of productivity.

Although the overall purpose of the paper was to advance our understanding of IT value creation, it may also have practical value. In this context, there is a limitation concerning the application of the model. Specifically, although the integrative model is based on prior 
IMDS

120,10

1934

empirical research, the practical applicability remains to be tested, for example, by case study research. In this context, it should be noted that the examples identified in the literature (Table 5) support the model's practical relevance.

Another future research avenue could be to investigate whether the extent of the moderating role of IT varies according to competitive positioning. For example, IT tools with transactional capabilities and the ability to automate processes might have a stronger effect on improving efficiency than on fostering innovativeness. Similarly, IT with primarily codification capabilities might impact innovation more than efficiency. This might be because innovation is tightly coupled with knowledge and the availability of knowledge, whereas efficiency enhancements are related to process improvements. Therefore, an IT tool with codification capabilities might make a stronger contribution to innovation (as the knowledge base for innovation) than to efficiency. As the inherent capabilities of IT might differ in their effect on the four dimensions of competitive advantage, it would be interesting to determine which combination yields the strongest and weakest results. Such insights could advance the field by highlighting the "better" fit of IT tools for a given purpose, thus leading to the optimization of the "value-for-money" of IT.

Another interesting research path would be to derive meaningful measurements or key performance indicators for each individual dimension. For example, efficiency-enhancing IT can be captured in productivity gains (Thatcher and Oliver, 2001), whereas quality improvements in customer service might be measured by increased customer satisfaction or brand reputation (Mithas et al., 2016). Nevertheless, there is a strong interest in expressing the value of IT in financial terms. Therefore, scholars are invited to build upon the advances made in our understanding of the differential effects of IT and to determine a financial IT value model that can account for the differential effects of firms' IT assets holistically.

\section{Conclusion}

To understand the value of IT, it is important to reflect on not only the conditions under which IT creates value but also the means by which it creates value. Therefore, this study contributes to IT research in two ways: (1) by improving our understanding of IT value creation by conceptualizing and defining the inherent capabilities of IT and (2) by describing the effects of these capabilities on efficiency, quality, innovation and customer responsiveness. In other words, this paper contributes by conceptualizing an aspect of IT value creation and by highlighting the moderating role of IT in competitive positioning.

The derived inherent capabilities of IT include transactional, exchange and codification capabilities, which reflect how IT moderates competitive positioning. Each IT system can be characterized by at least one of these three inherent capabilities. Depending on the context in which the IT system is deployed, the respective inherent capabilities impact efficiency, quality, innovation and customer responsiveness differently. Thus, linking the inherent capabilities of IT to the dimensions of competitive advantage constitutes a novel way of understanding IT value creation and its differential value contributions.

\section{Note}

1. www.scimagojr.com/journalrank.php

\section{References}

Adjerid, I., Adler-Milstein, J. and Angst, C.M. (2018), "Reducing Medicare spending through electronic health information exchange: the role of incentives and exchange maturity", Information Systems Research, Vol. 29, pp. 341-361, doi: 10.1287/isre.2017.0745. 
Altinkemer, K., Ozcelik, Y. and Ozdemir, Z.D. (2011), "Productivity and performance effects of business process reengineering: a firm-level analysis", Journal of Management Information Systems, Vol. 27, pp. 129-162, doi: 10.2753/mis0742-1222270405.

Angst, C.M., Devaraj, S. and D’Arcy, J. (2012), "Dual role of IT-assisted communication in patient care: a validated structure-process-outcome framework", Journal of Management Information Systems, Vol. 29, pp. 257-292, doi: 10.2753/mis0742-1222290209.

Aral, S. and Weill, P. (2007), "IT assets, organizational capabilities, and firm performance: how resource allocations and organizational differences explain performance variation", Organizational Science, Vol. 18, pp. 763-780, doi: 10.1287/orsc.1070.0306.

Aral, S., Brynjolfsson, E. and Van Alstyne, M. (2012), "Information, technology and information worker productivity”, Information Systems Management, Vol. 23, pp. 849-867.

Barczak, G., Sultan, F. and Hultink, E.J. (2007), "Determinants of IT usage and new product performance", Journal of Production Innovation Management, Vol. 24, pp. 600-613.

Byrd, T.A., Thrasher, E.H., Lang, T. and Davidson, N.W. (2006), "A process-oriented perspective of IS success: examining the impact of IS on operational cost”, Omega, Vol. 34, pp. 448-460, doi: 10. 1016/j.omega.2005.01.012.

Chou, Y.C., Chuang, H.H.-C. and Shao, B.B.M. (2014), "The impacts of information technology on total factor productivity: a look at externalities and innovations", International Journal of Production Economics, Vol. 158, pp. 290-299, doi: 10.1016/j.jpe.2014.08.003.

Chwelos, P., Ramirez, R., Kraemer, K.L. and Melville, N.P. (2010), "Does technological progress alter the nature of information technology as a production input? New evidence and new results", Information Systems Research, Vol. 21, pp. 392-408, doi: 10.1287/isre.1090.0229.

Davamanirajan, P., Kauffman, R.J., Kriebel, C.H. and Mukhopadhyay, T. (2006), "Systems design, process performance, and economic outcomes in international banking", Journal of Management Information Systems, Vol. 23, pp. 65-90, doi: 10.2753/mis0742-1222230204.

Dedrick, J., Gurbaxani, V. and Kraemer, K.L. (2003), "Information technology and economic performance: a critical review of the empirical evidence", ACM Computing Surveys, Vol. 35, pp. 1-28, doi: 10.1145/641865.641866.

Devaraj, S. and Kohli, R. (2000), "Information technology payoff in the health-care industry: a longitudinal study", Journal of Management Information Systems, Vol. 16, pp. 41-67, doi: 10. 1080/07421222.2000.11518265.

Devaraj, S. and Kohli, R. (2003), "Performance impacts of information technology: is actual usage the missing link?”, Management Science, Vol. 49, pp. 273-289, doi: 10.1287/mnsc.49.3.273.12736.

Dewett, T. and Jones, G.R. (2001), "The role of information technology in the organization: a review, model, and assessment", Journal of Management, Vol. 27, pp. 313-346, doi: 10.1016/s01492063(01)00094-0.

Dominguez-Péry, C., Ageron, B. and Neubert, G. (2013), "A service science framework to enhance value creation in service innovation projects. An RFID case study", International Journal of Production Economics, Vol. 141, pp. 440-451, doi: 10.1016/j.jpe.2011.12.026.

Dong, J.Q. and Wu, W. (2015), "Business value of social media technologies: evidence from online user innovation communities", Journal of Strategic Information Systems, Vol. 24, pp. 113-127, doi: 10. 1016/j.jsis.2015.04.003.

Fazlollahi, A. and Franke, U. (2018), "Measuring the impact of enterprise integration on firm performance using data envelopment analysis", International Journal of Production Economics, Vol. 200, pp. 119-129, doi: 10.1016/j.jpe.2018.02.011.

Feller, J., Finnegan, P. and Nilsson, O. (2011), "Open innovation and public administration: transformational typologies and business model impacts", European Journal of Information Systems, Vol. 20, pp. 358-374, doi: 10.1057/ejis.2010.65. 
IMDS

120,10

1936

Gardner, J.W., Boyer, K.K. and Gray, J.V. (2015), "Operational and strategic information processing: complementing healthcare IT infrastructure", Journal of Operations Management, Vol. 33 No. 34, pp. 123-139, doi: 10.1016/j.jom.2014.11.003.

Gioia, D.A., Corley, K.G. and Hamilton, A.L. (2012), "Seeking qualitative rigor in inductive research: notes on the Gioia methodology", Organization Research Methods, Vol. 16, pp. 15-31, doi: 10. 1177/1094428112452151.

Hackett, G.P. (1990), "Investment in technology - the service sector sinkhole?", Sloan Management Review, Vol. 31, pp. 97-103.

Hong, T.S. and Ghobakhloo, M. (2013), "IT investments and product development effectiveness: Iranian SBs", Industrial Management and Data Systems, Vol. 113, pp. 265-293, doi: 10.1108/ 02635571311303578.

Joshi, K.D., Chi, L., Datta, A. and Han, S. (2010), "Changing the competitive landscape: continuous innovation through IT-enabled knowledge capabilities", Information Systems Research, Vol. 21, pp. 472-495, doi: 10.1287/isre.1100.0298.

Khayer, A., Bao, Y. and Nguyen, B. (2020), "Understanding cloud computing success and its impact on firm performance: an integrated approach", Industrial Management and Data Systems, Vol. 120 No. 5, doi: 10.1108/IMDS-06-2019-0327.

Kim, T.H., Wimble, M. and Sambamurthy, V. (2018), "Disaggregation of the IT capital effects on firm performance: empirical evidence from an IT asset portfolio perspective", European Journal of Information Systems, Vol. 27, pp. 449-469, doi: 10.1057/s41303-017-0062-1.

Lai, F., Zhao, X. and Wang, Q. (2006), "The impact of information technology on the competitive advantage of logistics firms in China”, Industrial Management and Data Systems, Vol. 106, pp. 1249-1271, doi: 10.1108/02635570610712564.

Leidner, D.E. and Kayworth, T. (2006), "A review of culture in information systems research: toward a theory of information technology culture conflict”, MIS Quarterly, Vol. 30, pp. 357-399.

Leidner, D.E., Preston, D. and Chen, D. (2010), "An examination of the antecedents and consequences of organizational IT innovation in hospitals", Journal of Strategic Information Systems, Vol. 19, pp. 154-170, doi: 10.1016/j.jsis.2010.07.002.

Liang, T.-P., You, J.-J. and Liu, C.-C. (2010), “A resource-based perspective on information technology and firm performance: a meta-analysis", Industrial Management and Data Systems, Vol. 110, pp. 1138-1158, doi: 10.1108/02635571011077807.

Lowry, P.B., Moody, G.D., Gaskin, J., Galletta, D.F., Humpherys, S.L., Barlow, J.B. and Wilson, D.W. (2013), "Evaluating journal quality and the association for information systems senior scholars' journal basket via bibliometric measures: do expert journal assessments add value?”, MIS Quarterly, Vol. 37, pp. 993-1012.

Mauerhoefer, T., Strese, S. and Brettel, M. (2017), "The impact of information technology on new product development performance", Journal of Production Innovation Management, Vol. 34, pp. 719-738, doi: 10.1111/jpim.12408.

Meixell, M.J. (2006), "Quantifying the value of web services in supplier networks", Industrial Management and Data Systems, Vol. 106, pp. 407-422, doi: 10.1108/02635570610653524.

Melville, N.P., Kraemer, K. and Gurbaxani, V. (2004), "Review: information technology and organizational performance: an integrative model of it business value”, MIS Quarterly, Vol. 28, pp. 283-322.

Mistry, J.J. (2006), "Differential impacts of information technology on cost and revenue driver relationships in banking", Industrial Management and Data Systems, Vol. 106, pp. 327-344, doi: 10.1108/02635570610653489.

Mithas, S., Ramasubbu, N. and Sambamurthy, V. (2011), "How information management capability influences firm performance”, MIS Quarterly, Vol. 35, pp. 237-256, doi: 10.2307/23043496. 
Mithas, S., Krishnan, M.S. and Fornell, C. (2016), "Information technology, customer satisfaction, and profit: theory and evidence", Information Systems Research, Vol. 27, pp. 166-181, doi: 10.1287/ isre.2015.0609.

Müller, O., Fay, M. and vom Brocke, J. (2018), "The effect of big data and analytics on firm performance: an econometric analysis considering industry characteristics", Journal of Management Information Systems, Vol. 35, pp. 488-509, doi: 10.1080/07421222.2018.1451955.

Mukhopadhyay, T., Rajiv, S. and Srinivasan, K. (1997), "Information technology impact on process output and quality", Management Science, Vol. 43, pp. 1645-1659.

Effects of IT on competitive positioning

Neumeier, A., Wolf, T., Fridgen, G., Müller, H.V. and Reith, C. (2017), "Natural and design science perspective on the business value of IT", Americas Conference on Information Systems, Association for Information Systems (AIS), Boston, pp. 1-10.

Pang, M.-S., Lee, G. and Delone, W.H. (2014), "IT resources, organizational capabilities, and value creation in public-sector organisations: a public-value management perspective", Journal of Information Technology, Vol. 29, pp. 187-205, doi: 10.1057/jit.2014.2.

Po-An Hsieh, J.J., Rai, A., Xu, S.X., Hsieh, J.J.P.-A., Rai, A. and Xu, S.X. (2011), "Extracting business value from IT: a sensemaking perspective of post-adoptive use", Management Science, Vol. 57, pp. 2018-2039, doi: 10.1287/mnsc.1110.1398.

Porter, M.E. (1985), “Technology and competitive advantage”, Journal of Business Strategy, Vol. 5, pp. 60-78.

Ravichandran, T. (2018), "Exploring the relationships between it competence, innovation capacity and organizational agility", Journal of Strategic Information Systems, Vol. 27, pp. 22-42, doi: 10.1016/ j.jsis.2017.07.002.

Reyes, P.M., Li, S. and Visich, J.K. (2012), "Accessing antecedents and outcomes of RFID implementation in health care", International Journal of Productions Economics, Vol. 136, pp. 137-150, doi: 10.1016/j.jpe.2011.09.024.

Roberts, N. and Grover, V. (2012), "Leveraging information technology infrastructure to facilitate a firm's customer agility and competitive activity: an empirical investigation", Journal of Management Information Systems, Vol. 28, pp. 231-270, doi: 10.2753/mis0742-1222280409.

Saldanha, T.J.V. V., Mithas, S. and Krishnan, M.S. (2017), "Leveraging customer involvement for fueling innovation: the role of relational and analytical information processing capabilities", MIS Quarterly, Vol. 41, pp. 267-286, doi: 10.25300/misq/2017/41.1.14.

Schryen, G. (2013), "Revisiting IS business value research: what we already know, what we still need to know, and how we can get there", European Journal of Information Systems, Vol. 22, pp. 139-169, doi: 10.1057/ejis.2012.45.

Tambe, P. (2014), "Big data investment, skills, and firm value", Management Science, Vol. 60, pp. 1452-1469.

Thatcher, M.E. and Oliver, J.R. (2001), “The impact of technology investments on a firm's production efficiency, product quality, and productivity", Journal of Management Information Systems, Vol. 18, pp. 17-45, doi: 10.1080/07421222.2001.11045685.

Thorogood, A., Yetton, P., Vlasic, A. and Spiller, J. (2004), "Raise your glasses - the water's magic! Strategic IT at SA water: a case study in alignment, outsourcing and governance", Journal of Information Technology, Vol. 19, pp. 130-139, doi: 10.1057/palgrave.jit.2000017.

Trantopoulos, K., Von Krogh, G., Wallin, M.W. and Woerter, M. (2017), "External knowledge and information technology: implications for process innovation performance”, MIS Quarterly, Vol. 41, pp. 287-300.

Wiengarten, F., Humphreys, P., Cao, G. and McHugh, M. (2013), "Exploring the important role of organizational factors in it business value: taking a contingency perspective on the resourcebased view", International Journal of Management Review, Vol. 15, pp. 30-46, doi: 10.1111/j.14682370.2012.00332.x. 
IMDS

120,10
Xue, L., Ray, G. and Sambamurthy, V. (2012), "Efficiency or innovation: how do industry environments moderate the effects of firms' IT asset portfolios?", MIS Quarterly, Vol. 36, pp. 509-528, doi: 10.2307/41703465.

Zhu, K. and Kraemer, K.L. (2005), "Post-adoption variations in usage and value of e-business by organizations: cross-country evidence from the retail industry", Information Systems Research, Vol. 16, pp. 61-84, doi: 10.1287/isre.1050.0045. 
Appendix 1

Journal article codification

Effects of IT on competitive positioning

\begin{tabular}{|c|c|c|c|c|c|c|c|c|c|c|c|c|c|c|c|c|}
\hline \multirow[b]{2}{*}{ 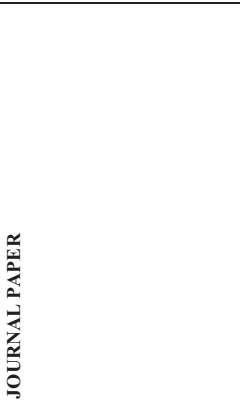 } & \multicolumn{4}{|c|}{$\begin{array}{l}\text { COMPETITIVE } \\
\text { ADVANTAGE }\end{array}$} & \multicolumn{3}{|c|}{ EFFICIENCY } & \multicolumn{3}{|c|}{ QUALITY } & \multicolumn{3}{|c|}{ INNOVATION } & \multicolumn{3}{|c|}{$\begin{array}{c}\text { CUSTOMER } \\
\text { RESPONSIVE } \\
\text { NESS }\end{array}$} \\
\hline & $\begin{array}{l}\text { 己े } \\
\text { Z } \\
\text { 至 } \\
\text { 厔 }\end{array}$ & 宓 & 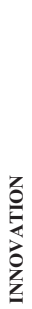 & 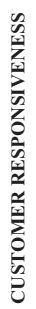 & 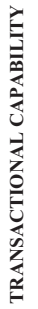 & 竞 & 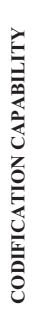 & 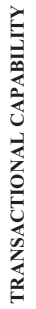 & 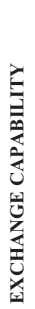 & 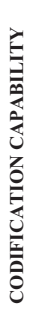 & 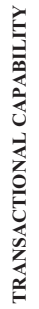 & 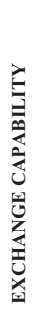 & 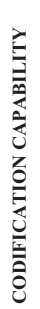 & 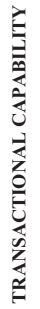 & 至 & 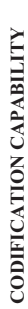 \\
\hline Adjerid et al., 2018 & 1 & 0 & 0 & 0 & 1 & 1 & 1 & 0 & 0 & 0 & 0 & 0 & 0 & 0 & 0 & 0 \\
\hline Angst et al., 2012 & 1 & 1 & 0 & 1 & 1 & 1 & 0 & 1 & 1 & 1 & 0 & 0 & 0 & 0 & 0 & 0 \\
\hline Aral and Weill, 2007 & 1 & 0 & 1 & 1 & 1 & 0 & 0 & 0 & 0 & 0 & 1 & 0 & 0 & 1 & 1 & 1 \\
\hline Barczak et al., 2007 & 0 & 0 & 0 & 1 & 0 & 0 & 0 & 0 & 0 & 0 & 0 & 0 & 0 & 0 & 1 & 1 \\
\hline Chou et al., 2014 & 1 & 0 & 0 & 0 & 1 & 1 & 1 & 0 & 0 & 0 & 0 & 0 & 0 & 0 & 0 & 0 \\
\hline Chwelos et al., 2010 & 1 & 0 & 0 & 0 & 1 & 0 & 0 & 0 & 0 & 0 & 0 & 0 & 0 & 0 & 0 & 0 \\
\hline Davamanirajan et al., 2006 & 1 & 0 & 0 & 0 & 1 & 1 & 0 & 0 & 0 & 0 & 0 & 0 & 0 & 0 & 0 & 0 \\
\hline Devaraj and Kohli, 2000 & 1 & 1 & 0 & 0 & 1 & 0 & 1 & 1 & 0 & 1 & 0 & 0 & 0 & 0 & 0 & 0 \\
\hline Devaraj and Kohli, 2003 & 1 & 1 & 0 & 0 & 1 & 0 & 1 & 1 & 0 & 1 & 0 & 0 & 0 & 0 & 0 & 0 \\
\hline Dewett and Jones, 2001 & 1 & 1 & 1 & 0 & 1 & 1 & 1 & 0 & 0 & 1 & 0 & 1 & 1 & 0 & 0 & 0 \\
\hline Dominguez-Péry et al., 2013 & 1 & 1 & 0 & 0 & 0 & 0 & 1 & 0 & 0 & 1 & 0 & 0 & 0 & 0 & 0 & 0 \\
\hline Dong and $\mathrm{Wu}, 2015$ & 0 & 0 & 1 & 1 & 0 & 0 & 0 & 0 & 0 & 0 & 0 & 1 & 1 & 0 & 1 & 1 \\
\hline Fazlollahi and Franke, 2018 & 1 & 0 & 0 & 0 & 1 & 1 & 0 & 0 & 0 & 0 & 0 & 0 & 0 & 0 & 0 & 0 \\
\hline Feller et al., 2011 & 1 & 1 & 0 & 0 & 1 & 0 & 0 & 1 & 1 & 0 & 0 & 0 & 0 & 0 & 0 & 0 \\
\hline Gardner et al., 2015 & 0 & 1 & 0 & 1 & 0 & 0 & 0 & 1 & 0 & 1 & 0 & 0 & 0 & 1 & 0 & 1 \\
\hline Joshi et al., 2010 & 0 & 0 & 1 & 0 & 0 & 0 & 0 & 0 & 0 & 0 & 1 & 1 & 0 & 0 & 0 & 0 \\
\hline Leidner et al., 2010 & 1 & 1 & 0 & 0 & 1 & 1 & 1 & 1 & 1 & 1 & 0 & 0 & 0 & 0 & 0 & 0 \\
\hline Mauerhoefer et al., 2017 & 1 & 0 & 1 & 0 & 1 & 1 & 1 & 0 & 0 & 0 & 1 & 1 & 1 & 0 & 0 & 0 \\
\hline Mithas et al., 2011 & 0 & 0 & 0 & 1 & 0 & 0 & 0 & 0 & 0 & 0 & 0 & 0 & 0 & 1 & 1 & 1 \\
\hline Mukhopadhyay et al., 1997 & 1 & 1 & 0 & 0 & 1 & 0 & 0 & 1 & 0 & 0 & 0 & 0 & 0 & 0 & 0 & 0 \\
\hline Müller et al., 2018 & 1 & 0 & 0 & 0 & 1 & 0 & 0 & 0 & 0 & 0 & 0 & 0 & 0 & 0 & 0 & 0 \\
\hline Pang et al., 2014 & 1 & 1 & 0 & 1 & 1 & 1 & 0 & 1 & 1 & 1 & 0 & 0 & 0 & 0 & 1 & 1 \\
\hline Po-An Hsieh et al., 2011 & 0 & 0 & 0 & 1 & 0 & 0 & 0 & 0 & 0 & 0 & 0 & 0 & 0 & 1 & 0 & 0 \\
\hline Ravichandran, 2018 & 0 & 0 & 0 & 1 & 0 & 0 & 0 & 0 & 0 & 0 & 0 & 0 & 0 & 1 & 1 & 0 \\
\hline Reyes et al., 2012 & 1 & 1 & 0 & 0 & 1 & 1 & 1 & 1 & 1 & 1 & 0 & 0 & 0 & 0 & 0 & 0 \\
\hline Saldanha et al., 2017 & 0 & 0 & 1 & 0 & 0 & 0 & 0 & 0 & 0 & 0 & 1 & 0 & 1 & 0 & 0 & 0 \\
\hline Tambe, 2014) & 1 & 0 & 0 & 0 & 1 & 0 & 1 & 0 & 0 & 0 & 0 & 0 & 0 & 0 & 0 & 0 \\
\hline Thorogood et al., 2004 & 1 & 1 & 0 & 0 & 1 & 0 & 0 & 1 & 0 & 0 & 0 & 0 & 0 & 0 & 0 & 0 \\
\hline Trantopoulos et al., 2017 & 1 & 0 & 0 & 0 & 1 & 1 & 1 & 0 & 0 & 0 & 0 & 0 & 0 & 0 & 0 & 0 \\
\hline Zhu and Kraemer, 2005 & 1 & 0 & 0 & 0 & 1 & 1 & 0 & 0 & 0 & 0 & 0 & 0 & 0 & 0 & 0 & 0 \\
\hline Absolute Count & 22 & 12 & 6 & 8 & 21 & 12 & 11 & 10 & 5 & 9 & 4 & 4 & 4 & 5 & 6 & 6 \\
\hline Relative Count & 71 & 39 & 19 & 26 & 68 & 39 & 35 & 32 & 16 & 29 & 13 & 13 & 13 & 16 & 19 & 19 \\
\hline & $\%$ & $\%$ & $\%$ & $\%$ & $\%$ & $\%$ & $\%$ & $\%$ & $\%$ & $\%$ & $\%$ & $\%$ & $\%$ & $\%$ & $\%$ & $\%$ \\
\hline
\end{tabular}

\section{Corresponding author}

Michael Bayer can be contacted at: michi-bayer@gmx.net

For instructions on how to order reprints of this article, please visit our website:

www.emeraldgrouppublishing.com/licensing/reprints.htm

Or contact us for further details: permissions@emeraldinsight.com 